\title{
Other Minds Are Neither Seen Nor Inferred
}

\author{
Mason Westfall*
}

\begin{abstract}
How do we know about other minds on the basis of perception? The two most common answers to this question are that we literally perceive others' mental states, or that we infer their mental states on the basis of perceiving something else. In this paper, I argue for a different answer. On my view, we don't perceive mental states, and yet perceptual experiences often immediately justify mental state attributions. In a slogan: other minds are neither seen nor inferred. I argue that this view offers the best explanation of our deeply equivocal intuitions about perception-based mental state attributions, and also holds substantial interest for the epistemology of perception more generally.
\end{abstract}

\section{Word Count: 7440}

Often we ascribe mental states on the basis of what we see. But how, exactly, do our visual experiences contribute to these attributions? This question is challenging, in part, because there are strong competing pressures on an acceptable answer. On the one hand, often our mental state ascriptions seem to result directly from what we see. I look at your face, and can just tell that you are enjoying yourself. On the other, the view that we literally see mental states strikes many people as highly counterintuitive. The contemporary literature has struggled to explain our equivocal intuitions about perception-based mental state ascriptions. Here I explain how these ascriptions can be direct, despite our not perceiving mental states. In particular, I argue that our mental state ascriptions are often immediately justified by visual experiences, despite mental states not being perceptually presented. On my view, we should give up an overly narrow conception of perceptual justification, on which perceptual experiences immediately justify only judgments that correspond to what is perceptually presented. If we give up this narrow conception, we can explain the uniquely puzzling features of perception-based mental state ascriptions.

*I would like to thank Jennifer Nagel, David James Barnett, Diana Raffman, Imogen Dickie, Eleonore Neufeld, Aaron Henry, Elliot Carter, Evan Westra, Manish Oza, Melissa Rees, audience members at the 2019 Eastern Division meeting of the American Philosophical Association-especially Zoe Jenkin and Amogha Sahu, and at the 2019 Annual Congress of the Canadian Philosophical Association-especially Madeleine Ransom. I would also like to thank two anonymous reviewers, whose thoughtful, incisive comments improved this paper immensely. 


\section{Preliminaries}

I hold that other minds are neither seen nor inferred. Let me explain what I mean. I take visual experiences to consist in the phenomenally conscious presentation of distal objects and properties. Something is 'seen', in my sense, if it is among the objects and properties that are presented in visual experience. ${ }^{1}$ So, to say that other minds are not seen is to say that others' minds and mental states are not presented in visual experience. So, the first claim I endorse is Invisibility, rather than Perceptualism.

Invisibility Others' mental states are not presented in visual experiences.

Perceptualism Others' mental states are sometimes presented in visual experiences.

Philosophers and psychologists do not uniformly use 'seen' and cognates as I am. For example, Eleanore Neufeld uses 'seen' and cognates to pick out a basic level of concept application to visual stimuli in her recent discussion of the same topic (Neufeld 2018, 4). I agree with Neufeld that basic concept applications to visual stimuli are important, but I prefer not to pick them out using 'seen' and cognates. Rather, I use 'perceptual judgments' to pick out basic concept applications. ${ }^{2}$ My usage enables us to distinguish between what is perceptually presented and what is judged on the basis of what is presented. I think distinguishing between perceptual presentation and perceptual judgment is important, because it enables us to ask epistemological questions about the relationship between perceptual experience and perceptual judgment. ${ }^{3}$

One might wonder whether distinguishing between perceptual experience and perceptual judgment is worthwhile. Why not, instead, take perceptual judgment to be the culmination of perceptual processing, and just call that 'seeing'? I have no objection to calling perceptual judgment a component of 'perceptual processing', so long as we reserve a distinction between perceptual experience and perceptual judgment. For example, in cases of known illusion, perceptual experience and perceptual judgment diverge. When I perceive a Müller-Lyer illusion, I do not judge that the lines are unequal in length. I recognize the illusion, and judge that the lines are equal in length. Nonetheless, the lines visually appear unequal in length. I take it that the lines are visually presented as unequal, but that we do not perceptually judge them to be unequal. Others may mark the same distinction using other terms, but I take it to be an important distinction. ${ }^{4}$

\footnotetext{
${ }^{1}$ My usage of 'seen' and cognates is hence not synonymous with 'epistemic seeing'. How exactly to understand epistemic seeing is controversial, but it is generally agreed that epistemic seeing does not align with perceptual presentation. See (Dretske 1969; Cassam 2009; Spaulding 2015; Neufeld 2018).

${ }^{2}$ More precisely, I use 'perceptual judgments' to pick out basic concept applications performed by the subject. I wish to remain neutral on whether visual experiences might have conceptual structure. If so, I take the concept applications constitutive of visual presentation to be subpersonal.

${ }^{3}$ See, for example, (Siegel and Silins 2015; Peacocke 1992; Campbell 2002; Smithies 2016; Pryor 2000) for philosophers endeavoring to ask and answer questions of this sort.

${ }^{4}$ One could hold, instead, that in cases of known illusion we first judge the lines to be unequal, and then
} 
I also say that mental state attributions aren't inferred. Of course, this is too strong as stated. We often do draw inferences concerning others' mental states. My claim is that sometimes our mental state attributions are non-inferential. In my view, our most fundamental perception-based attributions are immediately justified by visual experience. A judgment is immediately justified by experience if its justification doesn't rest on holding other justified beliefs. ${ }^{5}$ So, I endorse directness, rather than inferentialism.

Directness Mental state attributions are often non-inferentially justified by visual experience.

Inferentialism Mental state attributions are never non-inferentially justified by visual experience.

Putting Invisibility and Directness together gives us the official statement of my view.

The Ampliative View Mental states are not presented in visual experiences, and our mental state attributions are often non-inferentially justified by visual experiences.

The Ampliative View entails that visual experiences can justify judgments that outstrip what is perceptually presented. I call perceptual judgments that outstrip what is perceptually presented 'ampliative perceptual judgments'. Now that we have stated the view precisely, we can turn to whether we should accept it.

\section{Intuitions About Other Minds}

What is intuitive to say about knowing that someone is angry on the basis of looking at their face? Many philosophers have characterized how perception-based mental state attributions seem to us:

Phenomenologically, our awareness of the mental states of other people can often seem immediate. It seems that we can just see someone's anger or fear, and our impression that a triangle in an animation display is chasing (trying to catch) a circle can seemingly be part of our perception of the event, not inferred in thought thereafter. (Carruthers 2015, 498)

Many people have the sense that we simply cannot know about the mental states of other individuals in the same way we know about ordinary material objects... H. H. Price, for example, describes the idea that we can have perceptual knowledge of another's mind as 'extremely paradoxical'. (Parrott 2017)

judge that they are equal. I disprefer understanding known illusions in terms of multiple inconsistent judgments. That said, the reader can accept the importance of the conceptual distinction in the text, even if they think the example I chose is not an instance of it. Thanks to an anonymous reviewer for pressing me on this example.

${ }^{5}$ My understadning of immediate justification is inspired by Jim Pryor (2000, 2005) 
"We see emotion." - As opposed to what? - We do not see facial contortions and make the inference that he is feeling joy, grief, boredom. We describe a face immediately as sad, radiant, bored, even when we are unable to give any other description of the features. - Grief, one would like to say, is personified in the face. (Wittgenstein 1980)

At first blush, [Perceptualism] seems utterly implausible. Emotions are not the sorts of things that can be perceived. Indeed, much of the motivation for adopting [Theory Theory] and [Simulation Theory] derives from the commonsense assumption that emotions are hidden from the senses and so must be inferred on the basis of something else. (Glazer 2018)

Even amongst those who accept that we secure perceptual knowledge of each other's mental features, there is a certain hesitancy. Implicitly or explicitly, it tends to be accepted that there is a difference in kind between our visual knowledge that some book is red and our spontaneous knowledge that, for example, the person before us is anxious. (McNeill 2019)

One could be forgiven for being a bit confused. How should we proceed, given the striking divergence in what people take to be intuitive about other minds? One approach would be to consult our own intuitions. Do they more closely align with the perceptualist, or the inferentialist? I won't take this approach. I'm not so confident that my own intuitions are more reliable than others'. Moreover, such an approach is apt to be dialectically ineffective. People who don't share my initial intuitions will likely be unmoved by my intuitive appeals.

Rather, I suggest that we take equivocal intuitions as a datum to be explained. Our goal should not be a view that vindicates our intuitions, but one that explains them. A satisfying account of perceptual access to other minds will explain why our intuitions are equivocal in the way that they are. The Ampliative View, I suggest, best explains our equivocal intuitions. So, by inference to the best explanation, we should accept The Ampliative View.

Here is the explanation offered by the proponent of The Ampliative View. The following two claims are true:

Invisibility Others' mental states are not presented in visual experiences.

Directness Mental state attributions are often non-inferentially justified by visual experiences.

Each of these claims explains an aspect of our intuitive response to the problem. Those of us intuitively inclined towards a perceptual view are attending to the directness of many mental state attributions, ${ }^{6}$ while those of us inclined towards an inferential view, are attending to Invisibility. The possibility of immediately justified beliefs that outstrip what

\footnotetext{
${ }^{6}$ Notice, in particular, how commonly perceptualists motivate Perceptualism by emphasizing the noninferential character of many mental state attributions.
} 
is perceptually presented is often overlooked, so the intuitions are taken to clash, and philosophers have felt forced to choose between them. But once we revise our views about the relationship between perceptual presentation and perceptual judgment, we can explain what is right about both Perceptualism and Inferentialism, although neither is complete.

\section{Other Minds are Not Seen}

On the Ampliative View, other minds are not seen. This section motivates Invisibility. I'll argue that the Ampliative View offers a more satisfying explanation of our intuitions, and the problem of other minds, than a perceptual view.

The Ampliative View offers a better explanation than Perceptualism of our equivocal intuitions. The Ampliative View holds that our equivocal intuitions are the result of our vacillating between Invisibility and Directness, both of which are true. Perceptualism is not as well-suited to explain our intuitive ambivalence. If mental states are perceptually presented, why should there be a distinctively equivocal intuitive pattern with respect to them? Flatfootedly, we would expect subjects to take their perceptual experiences at face value. If they did, they would take themselves to see mental states. So why do we find our intuitions to be equivocal in a way not found for dogs or cups?

More philosophically, The Ampliative View offers a more satisfying response to the problem of other minds than Perceptualism. We don't just want an account of why skepticism about other minds is false; we want an explanation of why there was a skeptical problem to begin with. On the Ampliative View, the explanation involves our overlooking the possibility of ampliative perceptual judgments. We erroneously assumed that visual experience could only immediately justify beliefs about what is perceptually presented. Although I think that assumption is false, it's understandable. By contrast, perceptualists are hard-pressed to explain why there is a problem of other minds in the first place. Of course, perceptualists have a good answer to the problem of other minds. The perceptualist simply appeals to their account of perceptual justification in general. But if Perceptualism were true, why would people think a distinctive skeptical problem about mental state attribution existed at all? If the perceptualist's phenomenological descriptions are taken at face value, we would expect skepticism about other minds to be just as gripping as skepticism about dogs or cups. After all, according to the perceptualist, both are perceptually presented. ${ }^{7}$ But we don't feel gripped by skepticism about dogs in the same way. Perceptualists are not well-positioned to explain why not. ${ }^{8}$ So I think that the Ampliative View

\footnotetext{
${ }^{7}$ Whether kind properties like dogs are perceptually presented is, of course, controversial. (See (Byrne and Siegel 2017) for opposing positions on the controversy.) I take it that perceptualists about other minds will tend also to endorse rich content views more generally. My point is that, compared to other purported sorts of rich content, other minds pose a distinctive epistemological problem. If we can't see dogs, then substitute a high level property that we can see.

${ }^{8}$ That a satisfying response to skepticism should explain skepticism's appeal in addition to explaining why skepticism is false is well-articulated by Nozick (1981).
} 
is preferable to Perceptualism in offering more satisfying explanations of our equivocal intuitions and the problem of other minds.

\section{Defusing Perceptualist Arguments}

A number of authors have presented interesting arguments for Perceptualism. In this section, I'll consider three arguments for Perceptualism: a phenomenal contrast argument, an argument from cognitive architecture, and an argument from perceptual adaptation. I'll argue that none of these arguments offers persuasive support for Perceptualism. ${ }^{9}$

\subsection{A Phenomenal Contrast Argument}

One argument for Perceptualism is an instance of the phenomenal contrast method. Susanna Siegel $(2006,2011)$ has applied the phenomenal contrast method to argue that visual experiences have a variety of 'rich' content. ${ }^{10}$ Here is how the phenomenal contrast method works: first, we locate a pair of experiences that are similar in most respects, but that intuitively differ in overall phenomenology for subjects enjoying them. Then, we argue that the overall phenomenal difference is best explained by one visual experience having, and the other lacking, the 'rich' content. Siegel calls this the 'phenomenal contrast method' (Siegel 2011, Chapter 3).

Here is Siegel's pair of cases for mental states: You happen upon a population of people who make a particular facial expression that you do not recognize. Over time, you come to learn that they are expressing doubt. Intuitively, your overall experience differs before and after you gain the capacity to recognize doubt in their faces. Siegel proposes that the best explanation of this phenomenal difference is that your visual experience comes to represent doubt (Siegel 2006, 499-500). ${ }^{11}$

Three responses to Siegel's argument are available. The first is to deny that the two cases differ in overall phenomenal character. The second is to accept that there is an overall phenomenal difference - that is, to accept Siegel's intuitive verdict-but to deny that the best explanation is a difference in the content of the visual experiences. The third is to accept

\footnotetext{
${ }^{9}$ For other arguments in favor of Perceptualism, see (Gallagher 2007; Gallagher and Hutto 2008; Gallagher 2008; Green 2010; Neufeld 2018) among others.

${ }^{10}$ Siegel only briefly considers mental states, about which she says the same argument 'seem[s] to go through' (Siegel 2006, 500). (She also appears amenable to the suggestion in (Siegel 2012), though she doesn't defend it there.)

${ }^{11}$ Siegel articulates her view, and the phenomenal contrast method, in terms of representational content. Nonetheless, the phenomenal contrast method does not essentially depend on a commitment to representationalism. Naïve realists also need to say which properties contribute to a subject's perceptual perspective, and can appeal to phenomenal contrast arguments to address this question. In the interest of brevity, I will follow Siegel in occasionally lapsing into a representationalist idiom, with the understanding that the question of which properties are presented in perception cross-cuts debates between representationalists and naïve realists.
} 
both the overall phenomenal difference and the rich content explanation Siegel proposes. For mental states, the second response is advisable.

Commonly, commentators suggest that attentional differences explains the relevant phenomenal differences. ${ }^{12}$ When we come to be able to recognize objects of a particular kind, we deploy our perceptual attention differently. We stop attending to features that are not relevant for recognition and attend more closely to those that are relevant. Given that changes in perceptual attention plausibly change perceptual experience, ${ }^{13}$ this change in how we attend to low-level features predicts an overall phenomenal difference.

If the attentional reply is a good one for kinds in general, then it is a good reply for mental states. The case of mental states also features special reason to endorse this explanation. Mental state attributions are especially apt to modulate how we deploy our attention. Others' mental states loom large for us, and this shows up in how we deploy our attention. When I attribute doubt to Ed, it changes what features of the environment are salient—'what is Ed doubtful of?'; it changes what behaviors are reasonable-'should I explain what a Rubik's cube is?'; and it changes what inferences are reasonable to draw'Maybe Ed has never seen one of these before'.

This brings us to a second reply: that the overall phenomenal difference is due to cognitive differences. When my beliefs about your mental states differ, my thoughts, intentions, desires and so on are apt to change. Philosophers are engaged in an ongoing debate about the existence of proprietary cognitive phenomenology. ${ }^{14}$ Even skeptics about proprietary cognitive phenomenology will grant that cognitive differences are associated with phenomenal differences. ${ }^{15}$

Additionally, mental state attributions are correlated with emotional experiences, which have their own phenomenology. Several mechanisms secure this correlation. We often experience metaemotions-emotional responses to others' emotions. I might feel frustrated that you're doubtful-'why won't you believe me?!'. We also experience 'emotional contagion'. We tend to 'catch' the emotions of the people around us. ${ }^{16}$ Finally, we empathize with others. ${ }^{17}$ Each of these mechanisms is well-documented. So they are extremely likely to ground an overall phenomenal difference in the imagined case. ${ }^{18}$

For Siegel's phenomenal contrast to be persuasive, we need a pair of cases in which

\footnotetext{
${ }^{12}$ This reply can be found in (Price 2009; Prinz 2013; Connolly 2014). Shannon Spaulding (2015) also points to attention in connection with phenomenal contrast arguments and perceiving mental states.

${ }^{13}$ See, for example, (Block 2010).

${ }^{14}$ Cognitive phenomenology is 'proprietary' if it is different in kind from sensory phenomenology. See the papers in (Bayne and Montague 2011) for a range of perspectives.

${ }^{15}$ They will account for these phenomenal differences in terms of sensory phenomenology e.g. inner speech or bodily phenomenology. See (Prinz 2007) and (Smithies 2013) for discussion.

${ }^{16}$ See, for example, (Hatfield, Cacioppo, and Rapson 1993; Barsade 2002; Parkinson 2011).

${ }^{17}$ See, for example, (De Vignemont and Singer 2006).

${ }^{18}$ Whether emotional contagion or empathy contribute to the explanation of how we attribute mental states is an open question. However that controversy is resolved, though, it's not controversial that a correlation exists, and that is sufficient to explain an overall phenomenal difference.
} 
none of these other differences is operative. Cases in which emotion attribution is not associated with any of the above changes are not particularly realistic. But, plausibly, the intuitive force of the phenomenal contrast is trading on these more realistic cases, in which emotion attributions are associated with myriad non-visual phenomenal differences. We simply don't have a good intuitive grasp of what bare recognition, absent any attentional, cognitive or emotional effects feels like. As such, the phenomenal contrast-which, I stress, is intuitively compelling-does not license positing rich visual content.

\subsection{An Argument from Cognitive Architecture}

Peter Carruthers (2015) argues that we often perceive mental states by appealing to a global workspace cognitive architecture. Global workspace architecture involves a number of 'consumer systems' with specific functions. Some representations are 'globally broadcasted', which means they are made available for use by various consumer systems. The consumer systems then take the globally broadcasted representations as input, and perform their own specialized computations. ${ }^{19}$ On Carruthers' view, global workspace theory is our best current theory of cognitive architecture. Carruthers argues that global workspace architecture supports Perceptualism.

We can reconstruct Carruthers' argument like this:

1. Conceptual and sensory processing is interactive during perception. ${ }^{20}$ (Empirical Evidence)

2. Perceptual judgments (about mental states) are access conscious. ${ }^{21}$ (Assumption)

3. Perceptual judgments are access conscious if and only if concepts are bound into perceptual files and globally broadcasted. ${ }^{22}$ (1, inference to the best explanation)

4. So, concepts (about mental states) are bound into perceptual files and globally broadcasted. $^{23}$ (from 2 and 3 )

5. If concepts (about mental states) are bound into perceptual files and globally broadcasted, then the properties those concepts pick out-mental states-are perceived. ${ }^{24}$ (Assumption)

\footnotetext{
${ }^{19}$ See (Baars 1993, 1997; Carruthers 2014) for discussion.

${ }^{20}$ (Carruthers 2015, 501-2).

${ }^{21}$ (Carruthers 2015, 499). Access consciousness was originally introduced by Ned Block, who characterized it as 'availability for use in reasoning and rationally guiding speech and action' (Block 1995, 227)

${ }^{22}$ (Carruthers 2015, 506). Carruthers substantiates this claim by arguing that there is empirical evidence against an amodal working memory system. For my purposes, I will grant Carruthers' preferred cognitive architecture, so I won't discuss that aspect of Carruthers' argument.

${ }^{23}$ (Carruthers 2015, 504-6)

${ }^{24}$ (Carruthers 2015, 506).
} 
6. So, mental states are perceived. (from 4 and 5)

Premises 3 and 5 are questionable. Carruthers supports premise 3 by noting a variety of interactions between concepts and perception and then observing:

Given that conceptual and nonconceptual representations interact so deeply and pervasively in perceptual processing, it makes more sense that both should be integrated into the results of that processing, and bound into object-files... Moreover, by supposing that concepts can be parts of conscious perception we can appeal to known mechanisms to explain how such concepts and perceptual judgments can become access-conscious... An inference to the best explanation then enables us to conclude that concepts are globally broadcast as component parts of perceptual states. (Carruthers 2015, 502-3)

So, given the richness of interaction between conceptual and perceptual processing, it 'makes more sense' that they would produce integrated representations. Moreover, if global workspace theory is our best theory of access consciousness, we have to respect the mechanisms identified as subserving the global workspace. On our best understanding of those mechanisms, only perceptually formatted representations can be globally broadcasted, and so, a fortiori access conscious. So, concepts figuring in perceptual judgments must 'be parts of' perceptual states, otherwise they cannot be globally broadcasted, and therefore cannot be access conscious.

One could also argue the other way around, though. Given that perceptual judgments are access conscious, and that perceptual judgments have conceptual contents-both claims that Carruthers accepts-conceptual contents can be access conscious. Nothing about perceptual judgments in particular figures in this argument. Any occurrent judgment is plausibly access conscious, ${ }^{25}$ and occurrent judgments are conceptual if anything is. So if an account of access consciousness cannot explain how conceptual contents can be access conscious, we should be skeptical that it really explains access consciousness at all.

Controversially, Carruthers rejects the line of thought in the preceding paragraph. He holds that occurrent judgments themselves are not access conscious. Instead, they cause episodes of e.g. inner speech, which are access conscious (Carruthers 2011, Chapters 3 and 4). Carruthers' restrictive conception of the representations that can be access conscious undermines premise 2-that perceptual judgments are access conscious. Given that most of what we initially took to be access conscious is, according to Carruthers, not access conscious, how can we determine what is access conscious? Premise 2 is not supported by the (true) observations that perceptual judgments are available for use in reasoning and rationally guiding speech and action, since these properties are shared with other judgments which Carruthers denies can be conscious. So, although I think premise 2 is true,

\footnotetext{
${ }^{25}$ Carruthers rejects this claim. See below for discussion.
} 
Carruthers owes us an explanation for why he thinks it's true, and the standard story is not available to him.

Now, I am not arguing that we should reject global workspace theory. But for global workspace theory to be a plausible account of access consciousness, it must explain how conceptual contents can be access conscious. Happily, a global workspace framework can explain how conceptual judgments are access conscious. Rather than identifying global broadcast and access consciousness, we can explain the latter in terms of the former. Take my judgment that Don DeLillo is a good author: pace Carruthers, this judgment is access conscious, at least by Block's official definition. ${ }^{26}$ This poses a prima facie problem for global workspace theory, as an account of access consciousness. As Carruthers emphasizes, we don't know how non-perceptual states could be globally broadcasted. The canonical response is to posit a perceptually formatted representation that 'stands in' for the judgment-most commonly, inner speech. ${ }^{27}$ So, on this proposal, what it is for my (conceptual) judgment to be access conscious is for an episode of (perceptually formatted) inner speech corresponding to it to be globally broadcasted. Notice, though, I don't perceive that Don DeLillo is a good author. Even assuming a perceptually formated representation with that content is globally broadcasted, it does not constitute a perception of anything.

Now consider premise 5-if concepts are bound into perceptual files and globally broadcasted, then the properties those concepts pick out are perceived. The previous paragraph contains a counterexample. Inner speech simply doesn't constitute perception of anything. Although inner speech has a perceptual format, it is not perception. Similarly, imagining a red tomato is perhaps constituted by a representation in a perceptual format, but is not perceiving a red tomato. ${ }^{28}$

There's also a deeper reason for caution. Suppose Carruthers is correct about the cognitive architecture, and that concepts get 'bound in' to perceptual representations. Let's also restrict our attention to the 'genuinely perceptual' cases, so no imagery. How should we understand these representations? Carruthers assumes that they should be understood as perceptual, and so anything therein represented is ipso facto perceived. But given that these representations are mixed-format, it's not obvious what the justification is for treating them as perceptual states simpliciter. More plausibly, we could say that this one representation constitutes both a perceptual state and a cognitive one, associated with the divergent representational formats. ${ }^{29}$ So we can accept Carruthers' preferred cognitive architecture,

\footnotetext{
${ }^{26}$ I.e. it is available for use in reasoning, and rationally guiding speech and action.

${ }^{27}$ See (Carruthers 2011, Chapters 3 and 4).

${ }^{28}$ One could reply that these are not genuine perceptual files, and so not counterexamples. But that response renders the argument invalid because equivocal. Premise 3 is true only if 'perceptual files' is understood to pick out a representational format. But Premise 5 requires that we read 'perceptual files' differently, since inner speech does have a perceptual format, but does not constitute perception.

${ }^{29}$ Compare: I believe my kitchen is next to my bedroom. I also believe John's bedroom is next to my bedroom. Perhaps both of these beliefs are constituted by one cognitive map from which I can extract spatial information. In that case, one representation constitutes many beliefs. In the same way, a globally broadcasted 'perceptual' state with various concepts 'bound in' might constitute both a perceptual experience and various perceptual
} 
without accepting Perceptualism.

\subsection{An Argument from Adaptation Effects}

Ned Block argues that we perceive mental states in another way. Block suggests that adaptation effects reveal that emotions are attributed to faces perceptually (Block 2014). ${ }^{30}$ In the crucial experiment, subjects were first presented with either an image of an angry or fearful facial expressions, and then presented with an expression that was ambiguous between anger and fear. Subjects were finally presented with an image of both the fearful and angry faces, and had to choose the one that looked more similar to the ambiguous face. Subjects who had adapted to a fearful expression rated the ambiguous expression as more similar to the subsequently presented angry face, and vice versa (Butler et al. 2008). Crucially, these effects were found only for images that presented a unified expression, not for faces constructed out of parts expressing different emotions. This indicates that the subjects are adapting to the expression, not merely low-level features like shape. Block takes adaptation to stimuli to indicate perceptual processing. Evidence supports the existence of many uncontroversially perceptual adaptation effects ${ }^{31}$ and, Block says, no evidence of conceptual adaptation effects (Block 2014, 567).

In fact, this experiment does not give us reason to posit perceptual representations of emotions. Subjects were asked to select the image-fearful or angry face-that appeared most similar to the ambiguous one (Butler et al. 2008, 124). There must be perceptual representations of faces, not merely shape, to explain this effect. Indeed, the claim that we have perceptual representations of faces is extremely plausible. But the experiment does not probe whether these representations involve emotion attributions. The same data are predicted by a view that posits 'neutral' representations of facial expressions-that is, facial expressions construed non-mentally.

Further, the experiment does not distinguish between two strategies subjects may employ. One possibility is that subjects hold a perceptual representation of the ambiguous face in working memory to compare with the two faces they are asked to choose between. Block tacitly assumes this is the strategy subjects are using, since only this strategy probes specifically perceptual representations. A second possibility, though, is that subjects judge the ambiguous face to be, say, angry and then store this judgment to compare with judgments about the unambiguous faces. On this hypothesis, subjects would rate the ambiguous face as more similar to the face that they judged to be expressing the same emotion. Indeed, the fact that similar adaptation effects were not found for inconsistent expressions seems to indicate subjects deployed the second strategy. But clearly, if subjects are deploying the second strategy, then the experiment does not indicate whether subjects have specifically perceptual representations of mental states.

judgments.

${ }^{30}$ Thanks to Zoe Jenkin for encouraging me to consider this argument.

${ }^{31}$ The waterfall illusion constitutes a canonical example. See (Addams 1834). 
So I think the Ampliative View is preferable to Perceptualism. The Ampliative View offers a satisfying explanation of our uniquely equivocal intuitions concerning perceptual access to mental states, and can explain why the problem of other minds seemed distinctively challenging. Perceptualism, by contrast urges us to take our perceptual access to other minds to be akin to our perceptual access to dogs or cups. As such, Perceptualism is not well-suited to explain what's distinctive about perceptual access to the mental. The arguments considered in favor of Perceptualism also seem unpersuasive. So I think there is substantial reason to prefer the Ampliative View to Perceptualism.

\section{Other Minds are not Inferred}

I now turn to Inferentialism. Recall, Inferentialism is the view that our perception-based mental state ascriptions are always inferentially mediated. Of course, inferentialists need not hold that our mental state ascriptions are always the result of conscious or deliberate inference. Often, inferences are fast and automatic. On the other hand, the inferentialist needs to offer some restriction on what counts as an inference. Some people use 'inference' and cognates so broadly that Inferentialism ceases to be a distinctive view. On these more capacious uses, inferences are pervasive in the cognitive system, since the cognitive system is an information processing system, and information processing is tantamount to inference. $^{32}$

I don't have any objection to this broader use per se, so long as we also allow for a more restrictive use. We need a more restrictive use in order to understand debates in the epistemology of perception. For example, Jim Pryor (2000) defends Dogmatism-the view that perceptual experience provides defeasible non-inferential justification to form certain beliefs. Whether or not we endorse Dogmatism, we are misunderstanding the thesis if we take it to be the claim that perception provides justification in the absence of any information processing whatsoever. Dogmatism is not inconsistent with a computational account of visual processing. Rather, the idea is that perception can justify beliefs in a way that doesn't rest on any background beliefs. I propose that we understand Inferentialism in the same spirit. According to the inferentialist, perception-based mental state attribution always rests on a subject's background beliefs (although this need not involve conscious, deliberate inference).

Inferentialism can explain why there seems to be a distinctive problem of other mindswe can't see mental states. ${ }^{33}$ The inferentialist also has an explanation of the intuitive directness. ${ }^{34}$ Often, the inferentialist points out, we make inferences quickly and fluently, without any conscious deliberation. For example, I may form the belief that I need gas on

\footnotetext{
${ }^{32}$ This more capacious perspective can be found in inferential theories of vision. See, for example (Hatfield 2002). The idea was canonically expressed by Helmholtz (1867/1924), and is plausibly older than that. Hohwy (2013) is a recent exponent of this usage.

${ }^{33}$ For an interesting recent development of an inferential view, see (Parrott 2017).

${ }^{34}$ Although they deny Directness, as I have specified it.
} 
the basis of looking at my gas gauge. Despite an absence of conscious deliberation, surely this belief is inferentially justified. ${ }^{35}$ Similarly, the inferentialist will suggest, I form a justified belief that your face looks thus and so, and infer that you are angry. This attribution is intuitively direct because it is phenomenologically fluent.

I won't consider whether this is an adequate vindication of the intuitive directness of mental state attributions. I'll argue, more ambitiously, that it isn't an available vindication. Some mental state attributions cannot be inferentially justified, so whether the inferentialist adequately explains the seeming directness of our attributions is beside the point. The view is false. ${ }^{36}$

One way to develop Inferentialism is to propose that we perceive that someone looks angry'. Looks can be developed either in a statistical way, or a factive way. ${ }^{37}$ On a statistical view, 'looking angry' depends on a statistical correlation between a certain appearance, and instances of anger. On a factive view, only actual instances of anger produce the look of anger. There may be other appearances that are indistinguishable to an observer, that nonetheless fail to be the look of anger, since they are produced by something other than anger. Parrott's motivation for the factive version is to vindicate Austin's observation that 'there is a peculiar and intimate relationship' between mental states and their expressions (Wisdom et al. 1946). ${ }^{38}$

But, how are we in a position to judge that one looks excited on the basis of our experience? In order for looks to constitute progress, the answer must be that perception presents looks as such. If not, we will be left with the same problem we began with, this time about looks instead of mental states. Namely, how do we know about looks on the basis of experiences that do not present looks?

The view that we see looks is implausible, though. Perception purports to present things as they are in the world. This apparently banal observation rules out contents like LOOKS EXCITED, though. Such a content would constitute perception presenting a mere appearance property. Attributing appearances derives from our understanding that our eyes are not always to be trusted. This is a cognitive achievement, not a perceptual one. Perception doesn't purport to present appearances, and so does not present looks. ${ }^{39}$

\footnotetext{
${ }^{35}$ The gas gauge example comes from Pryor (2005).

${ }^{36}$ For independent arguments against Inferentialism, see (McNeill 2015; Neufeld 2018). Although Neufeld sets up the debate substantially differently, I take her arguments to be relevant to my construal of Inferentialism as well.

${ }^{37}$ Parrott (2017) develops a factive account of looks; as I read him, Martin (2010) develops a statistical account. See also (Smith 2015) for an interestingly nuanced account of the relevant looks.

${ }^{38} \mathrm{~A}$ factive construal of looks is also floated by McDowell (1982), although he has distinctive epistemological motivations.

${ }^{39}$ Some philosophers use 'looks' to pick out the perspectival aspect of perceptual experience. For example, a round coin might look ovoid, while also looking round, and we might call the ovoid appearance a 'look' (Noë 2005). I take this to be a different sense of 'look' than the one at issue in 'looks excited'. On Noë's view, we perceive non-perspectival properties by perceiving perspectival properties. If we understand 'looks' as perspectival properties, then I take it that the proposed view would be a perceptual view, not an inferential
} 
If the preceding is right, though, then looks are not available to an inferential account. If we had the justified belief that somebody looked excited, we would be justified in moving to the belief that they were excited. But no explanation of how we are justified in believing that somebody looks excited is available. We are faced with the same problem we began with, now concerning perception-based beliefs about looks. So we should look for a different solution.

More generally, for beliefs about others' minds to be inferentially justified, there must be some other belief on which their justification rests. Such justifying beliefs are often elusive though. We are generally interested in how people are feeling, not how those feelings are visually manifest. I don't particularly care how my friend looks; I care how she's feeling. One could hold that, in forming beliefs about other's emotions, we first quickly form a belief about their facial configuration, infer the emotion on the basis of the facial configuration, and then-kicking away the ladder-quickly forget how they looked. This has some initial plausibility. After all, we know many things, despite being unable to remember quite how we learned them, and we routinely make fast, automatic inferences of the kind suggested.

The initial plausibility is fleeting, though. If the inferential view is correct, then we must be able to quickly and fluently categorize people's facial expressions, independent of the emotions they are expressing, and have general beliefs about how these facial expressions relate to emotions. According to the inferential view, these are both necessary components of attributing emotions on the basis of visual experience. So, given that we can attribute emotions in this way, we must meet the necessary preconditions. For some simple emotions this seems promising. We can easily recognize a smile, for example, and we plausibly have a justified belief that smiles are generally indications of happiness. ${ }^{40}$ This pattern does not generalize though. What general beliefs do we have about expressions of fear? Of course, we know that expressions of fear indicate fear. But how do we exploit that knowledge in recognizing fear? That is, how do we recognize an expression of fear? For Inferentialism to succeed, we must have general beliefs about the perceptible features that are diagnostic of an expression of fear. Admittedly, we have some-for example, I believe that expressions of fear generally involve widened eyes. Unfortunately, that belief won't be much help recognizing expressions of fear, because many other facial expressions also involve widened eyes. When I introspect, I find precious few beliefs about the features of fear expressions. It's implausible that the beliefs that I do have are sufficient to license the purported inferences that secure mental state attribution. ${ }^{41}$

view. I take it, instead, that the look of excitement is not meant to be a perspectival property. Rather, the look of excitement is a non-perspectival property of a face. I am denying that perception presents 'objective' mere appearances, not denying that perception presents perspectival properties.

${ }^{40}$ In fact, I'm skeptical Inferentialism is plausible even in this case. Smiles also indicate politeness, awkwardness, pain, finding something funny, and so on. We would need much more specific beliefs about which sorts of smiles indicate which sorts of mental states. So even in the most promising case for Inferentialism, there is some reason for doubt.

${ }^{41}$ Of course, that is not to say that we cannot recognize expressions of fear. Obviously we can. My point is 
Moreover, to the extent we do have beliefs about what features of facial expressions indicate about an expressed emotion, they are often erroneous. For example, people are often surprised to learn that neurotypical subjects are quite good at categorizing facial expressions from the eyes alone (Baron-Cohen et al. 2001), or that people generally cannot distinguish between expressions of extreme positive and negative emotion in a face without a bodily context (Aviezer, Trope, and Todorov 2012). Examples like these pose both a psychological and an epistemological problem for the inferentialist. First-psychologicallypeople's general beliefs about what perceptible features indicate about emotions are evidently not explaining emotion recognition. Perhaps subjects in Aviezer et al's study believe that the perceptible features of the face indicate, say, positive emotion, and yet, their recognition is demonstrably not sensitive to the perceptible features of the face, since the very same face would be taken to be expressing negative emotion on a different body. So there are serious reasons to doubt that the relevant general beliefs are involved in emotion recognition in the way the inferentialist suggests. Second-epistemologically-if we did rely on the sorts of general beliefs the inferentialist suggests, the justification of our mental state attributions would be threatened. Inferences from unjustified premises yield unjustified conclusions, so if our general beliefs are not well-founded, our mental state attributions may be unjustified as well. ${ }^{42}$ But if so, then Inferentialism struggles to explain how our mental state attributions are justified, even assuming it can answer the psychological problem.

We can think SHE LOOKS LIKE THAT. This demonstrative judgment on its own doesn't seem to license any particular judgment, though. What would license a judgment is the saturated demonstrative, and what it would license depends on how the demonstrative is saturated. So in order to move from the demonstrative judgment to the appropriate attribution, we need to respond to the experience itself. But then the judgment is immediately licensed by the experience-as I will suggest below-and the demonstrative judgment is otiose.

A final option is that we infer directly from the experience itself. But why should we consider this an inference? If we did, we would arguably be forced to hold that all perceptual judgments are inferential. But, I take it, perceptual judgments are importantly different from inferences. In ordinary circumstances, we do not take our experiences to be akin to premises from which we reason. Nor is it a requirement on a justified perceptual judgment that the experience on which it is based itself be justified. ${ }^{43}$ These are important differences between perceptual justification and the conclusion of an inference. We should mark these differences in our theorizing. Treating the justification characteristic of perceptual judgments as a species of inferential justification threatens to elide crucial epistemic

that in order for an inferential account to succeed, we would need to know a lot more about facial expressions than we seem to. Happily, there are non-inferential accounts that avoid this problem.

${ }^{42}$ The inferentialist could argue that our beliefs are justified but false, but then they owe us an explanation of how these erroneous beliefs are justified. It's not obvious to me that such an explanation can be made to work.

${ }^{43}$ Pace Siegel (2016), who notably dissents. 
distinctions. Of course we could say that these distinctions are between different kinds of inferential justification. At that point, the dispute is verbal. My preference is to reserve 'inferential justification' for the more specific case, and so to say that perceptual justification is 'non-inferential'. The substantive point, though, is that perceptual justification is different in kind from the canonical instances of inferential justification, and that perception-based mental state attributions are unlike canonical instances of inferential justification.

\section{Ampliative Perceptual Judgments}

I suggest taking a step back and considering perceptual justification in general. Directness and Invisibility are inconsistent assuming that we can know directly only those things that are perceptually presented. We should reject this assumption. The primary constraint on what subjects can know on the basis of perception is not what perception presents. Rather, subjects' recognitional capacities determine what they're in a position to know on the basis of experience. Crucially, recognitional capacities can outstrip perceptual presentation. Sometimes we judge what we see; sometimes we judge more than we see. I call the latter 'ampliative perceptual judgments'.

Our target cases are ampliative perceptual judgments. Visual experiences do not present mental states, but these experiences immediately justify beliefs about mental states, because subjects have the relevant recognitional capacities. This vindicates both Directness and Invisibility: mental states are not observable, but our attributions are the direct result of our experiences. ${ }^{4}$

What does it take for an experience to immediately justify a belief? Just having the experience is insufficient. One must also possess the relevant concepts. Without conceptual competence, we will not be able to form a judgment on the basis of the experience, and so our experience will fail to justify a belief. In addition to experience and conceptual competence, the relevant recognitional capacity is also a necessary condition for perceptual justification. Or so I will now argue.

Sometimes subjects have the requisite concepts to think a thought and an experience that would justify believing the content of that thought, but are still not in a position to form a justified belief. The best explanation of this is that they lack the relevant recognitional capacity. Take Marianna the color scientist. ${ }^{45}$ Marianna is a color scientist raised in a black and white room. She knows all of the physical facts about colors. She is then let into a room featuring brightly colored objects. These objects don't have canonical colors, so Marianna cannot work out which objects are which colors. Plausibly, Marianna can have the same color experience as someone with a more conventional history. ${ }^{46}$ Marianna also has

\footnotetext{
${ }^{44}$ Spaulding (2017) also argues that judgments about motor intentions are immediately justified. The motivations and understanding of basic beliefs are substantially different.

${ }^{45}$ This example is taken from Nida-Rümelin (2004), although she puts it to a different use.

${ }^{46}$ Though I won't argue for this claim, I will note two unpersuasive reasons for denying it: First, Marianna
} 
the relevant concepts. She is in a position to wonder whether the vase is red. So, she is in a position to think about redness as such. ${ }^{47}$ Nonetheless, Marianna is not in a position to perceptually judge THE VASE IS RED. Despite having the relevant experience and concepts, she cannot perceptually judge that the vase is red, because she lacks a recognitional capacity for redness.

This example is perhaps more controversial than it needs to be. Color concepts, more than other concepts, do seem to have a special connection to visual acquaintance. So perhaps it really isn't possible to possess the concept RED without being poised to recognize red visually. ${ }^{48}$ Perhaps this is true, but if so it supports the lesson I want to draw in any case. My point is that the relevant recognitional capacity is a necessary condition for perceptual justification. If it turns out that subjects can't even possess the concept RED in the absence of a recognitional capacity, then a fortiori they cannot form a perceptually justified judgment without a recognitional capacity. So even for maximally low-level visible properties, perceptual justification requires that subjects have a recognitional capacity.

The same dependence exists for more sophisticated properties. Suppose I go to Joshua Tree and begin wandering the desert. I have read quite a lot about the underlying biological properties of Joshua Trees-for which the region is named. I can locate Joshua Trees in the phylogenetic tree, and know a lot about them-growth rates, habitat, that they're likely to be severely disrupted due to climate change, ${ }^{49}$ and so on. Unfortunately, I don't manage to learn much about their appearance. There I am, wandering around Joshua Tree, possessing the concept JOSHUA TREE, and looking at a Joshua Tree, but unable to recognize it as such. ${ }^{50}$ I have the requisite concepts and am having the relevant experience, but my experience cannot justify my belief that THAT IS A JOSHUA TREE. Epistemically, I am like Marianna looking at red. We are both having an experience that would justify a belief, if only we had the relevant recognitional capacity. ${ }^{51}$

has not seen colors before and this may affect development of color vision. This is not essential to the case. Marianna could have grown up in the colored room without ever being in a position to figure out which color was which. Second, some people think color experience is often cognitively penetrated, e.g. (Macpherson 2012). So perhaps normal subjects would have a cognitively penetrated experience, which is thereby importantly different from Marianna's. The objects Marianna is looking at are not ones that ordinary subjects would have expectations about with respect to color, so the kind of cognitive penetration Macpherson discusses is not relevant. A normal subject's experiences would not be cognitively penetrated in the way Macpherson describes.

${ }^{47}$ Being in a possition to think about Fs as such is Fodor's (2004) characterization of concept possession. I use it here for convenience, but the point I am making doesn't turn on a commitment to this view of concepts.

${ }^{48}$ Though this thought has some initial plausibility, I think on reflection we should reject it. Recall that Marianna is meant to know all of the physical facts about color. If she does not possess the concept RED, it's hard to understand how she could have any beliefs about red, much less knowledge. The objector may respond that this just shows it's a badly conceived thought experiment. I disagree, but our disagreement is not relevant to the argument I'm making in the text, so I leave it aside.

${ }^{49}$ See (Cole et al. 2011).

${ }^{50}$ This example is adapted from (Loar 1990).

${ }^{51}$ Brian Loar-from whom I'm adapting this example-calls this a 'recognitional disposition' (Loar 1990, 88-90). I prefer 'recognitional capacity' because it's questionable whether recognitional capacities are best- 
Of course, whether we can perceive kind properties is controversial. I think we can, but whether or not we can perceive the property of being a Joshua Tree, our experience would support the judgment to that effect, if only we had the recognitional capacity. This suggests that however rich perceptual experience is exactly, we need not take that to be a constraint on the judgments that can be immediately justified by experience. Our recognitional capacities-not the richness of perceptual presentation-constrain our perceptual judgments.

To a first approximation, recognitional capacities are abilities to link up experiences of a certain kind to the relevant conceptual judgments. So without a recognitional capacity, we might have the relevant experience, and yet not be in a position to move to the corresponding judgment. Plausibly, not just any disposition to move from an experience kind to a judgment constitutes a recognitional capacity. A subject may have a disposition to judge that people with moustaches are smart. Presumably, such a subject is not thereby capable of recognizing smarts. A full account of recognitional capacities should distinguish these unhappy cases from genuine recognitional capacities.

How such an account is developed will depend on one's epistemological scruples, not least whether one is an internalist or externalist. I take the examples to show that recognitional capacities are a necessary component of any satisfactory account of perceptual justification. So both externalists and internalists should be optimistic that such an account is in the offing.

Recognitional capacities play a similar role to observational concepts in Christopher Peacocke's work (Peacocke 1992, 2001). Peacocke holds that the content of perceptual experiences is non-conceptual. This raises a prima facie challenge. Perceptual judgments have conceptual content. So how is it that non-conceptual contents put us in a position to judge conceptual contents? Peacocke appeals to observational concepts to answer this question. Observational concepts are concepts partly individuated by particular aspects of experience-for Peacocke, non-conceptual contents-to which they are 'rationally sensitive' (Peacocke 2001, 253). Peacocke's idea is that applying observational concepts on the strength of certain experiences alone is constitutive of concept possession. If you do not apply REGULAR DIAMOND in response to a particular kind of experience taken at face value, you do not have the REGULAR DIAMOND observational concept.

The work done by observational concepts is necessary, but we should resist positing a set of proprietary concepts. Fundamentally, the problem is that perceptual judgments deploy ordinary concepts, not proprietary ones. If we treat recognitional capacities as part of the possession conditions for the concepts deployed in perceptual judgments, then subjects who lack the recognitional capacities will also lack the relevant concepts-since responding to experience in this way is constitutive of concept possession. As I noted above, this may be plausible in the case of color properties, but the plausibility doesn't generalize. Recognitional capacities are abilities involving concepts, not a condition on concept pos-

understood as dispositions. I remain neutral on that question for present purposes. 
session. For a particularly clear example, consider the case of congenitally blind subjects. These subjects do not have visual recognitional capacities linking up experiences of facial expressions with emotion attribution. Nonetheless, they surely have the same stock of mental state concepts; they can understand the content I judge when I recognize a friend's anger.

The Ampliative View is generally neglected because many philosophers assume that perceptual justification works, in part, because of a match in content. So if perceptual experience does not include a content $\mathrm{P}$, it cannot immediately justify a belief that $\mathrm{P} .{ }^{52}$ On the view outlined here, an experience's epistemic import depends on the recognitional capacities of the person enjoying the experience. From my perspective, it is distorting to askabstracting away from a particular subject and their cognitive capacities-what judgments an experience justifies. ${ }^{53}$ The selfsame experience will have different epistemic import depending on the cognitive context in which it is enjoyed.

One might object that the Ampliative View collapses into an inferential view. After all, one way or another, recognitional capacities must encode information about a correlation between facial expressions and mental states. Without encoding such information, 'ampliative perceptual judgments' would be impossible. But if 'ampliative perceptual judgments' rely on stored information about a general correlation between mental states and facial expressions, then those judgments turn out to be inferential after all. ${ }^{54}$

I'm not persuaded by this objection. I take it that perceptual judgments also rely on information stored within the visual system-for example, that scenes are usually lit from overhead. ${ }^{55}$ Relying on encoded information in performing a cognitive task does not ipso facto render the performance inferential. Many cognitive processes are not inferential. On my view, inferences only occur between conceptually formatted contents. ${ }^{56}$ The cognitive system encodes information in many different formats, and when that information is encoded non-conceptually, transitions involving it are not inferential. ${ }^{57}$

\footnotetext{
${ }^{52}$ For prominent examples, see Pryor (2000) and Smithies (2011) who each propose that perceptual justification works by experience presenting contents in a distinctive way.

${ }^{53}$ And it is not surprising that asking what an experience justifies in the abstract would result in a restrictive answer, since-once we abstract from a subject and their cognitive capacities—all we have left is the content of the experience. Though, again, even for the case of low-level perceptible properties, recognitional capacities are required for justified perceptual judgments.

${ }^{54}$ Thanks to an anonymous reviewer for raising this objection.

${ }^{55}$ See, for example (Ramachandran 1988a, 1988b; Kleffner and Ramachandran 1992).

${ }^{56} \mathrm{My}$ thinking about inferences is consonant with quite disparate ways of thinking about what inference-in the more restrictive sense at issue-is. To take two paradigmatic examples, Boghossian (2014) offers a nonnatural account of inference-in terms of a primitive, normative notion of following a rule, while Quilty-Dunn and Mandelbaum (2018) offer a naturalistic account-in terms of transitions governed by syntactic rules that are built into the cognitive architecture of a system. Both restrict inference to transitions involving conceptual states like beliefs.

${ }^{57}$ See also (Beck 2012) for a persuasive argument that some extra-perceptual cognitive systems have a nonconceptual representational format.
} 


\section{Conclusion}

We know about other minds perceptually by judging beyond what is perceptually presented. My proposal offers a satisfying resolution to our initial puzzle. Once the epistemic import of recognitional capacities is appreciated, we can see that Directness and Invisibility are compatible. A perceptual judgment can issue directly from a perceptual experience, even without corresponding to what is perceptually presented. So the fact that the experience doesn't present mental states is not a reason to deny that the judgments are immediately justified by experience. The apparent tension is resolved. Happily, our investigation into mental state attribution has also uncovered an important epistemic category. Ampliative perceptual judgments bear philosophical attention well beyond their relevance to the problem of other minds. Discussions in the epistemology of perception and the philosophy of mind more generally are apt to be enriched by considering the full diversity of perceptual judgments we make.

\section{References}

Addams, R. 1834. "An account of a peculiar optical phenomenon seen after having looked at a moving body". The London, Edinburgh, and Dublin Philosophical Magazine and Journal of Science 5 (29): 373-374.

Aviezer, Hillel, Yaacov Trope, and Alexander Todorov. 2012. "Body cues, not facial expressions, discriminate between intense positive and negative emotions". Science 338 (6111): 1225-1229.

Baars, Bernard J. 1993. A cognitive theory of consciousness. Cambridge University Press.

- . 1997. "In the theatre of consciousness. Global workspace theory, a rigorous scientific theory of consciousness". Journal of Consciousness Studies 4 (4): 292-309.

Baron-Cohen, Simon, et al. 2001. "The "Reading the Mind in the Eyes" test revised version: A study with normal adults, and adults with Asperger syndrome or high-functioning autism". Journal of child psychology and psychiatry 42 (2): 241-251.

Barsade, Sigal G. 2002. “The ripple effect: Emotional contagion and its influence on group behavior". Administrative Science Quarterly 47 (4): 644-675.

Bayne, Tim, and Michelle Montague. 2011. Cognitive phenomenology. Oxford University Press on Demand.

Beck, Jacob. 2012. “The generality constraint and the structure of thought". Mind 121 (483): 563-600.

Block, Ned. 1995. “On a confusion about a function of consciousness". Behavioral and brain sciences 18 (2): 227-247.

— . 2010. “Attention and Mental Paint". Philosophical Issues 20 (1): 23-63. 
- . 2014. "Seeing-as in the light of vision science". Philosophy and Phenomenological Research 89 (3): 560-572.

Boghossian, Paul. 2014. “What is inference?" Philosophical Studies 169 (1): 1-18.

Butler, Andrea, et al. 2008. "Factors contributing to the adaptation aftereffects of facial expression". Brain research 1191:116-126.

Byrne, Alex, and Susanna Siegel. 2017. "Rich or Thin?" In Current Controversies in Philosophy of Perception, 59-80. Routledge.

Campbell, John. 2002. Reference and Consciousness. Oxford University Press.

Carruthers, Peter. 2011. The opacity of mind: An integrative theory of self-knowledge. OUP Oxford.

— . 2014. “On central cognition”. Philosophical Studies 170 (1): 143-162.

— . 2015. "Perceiving mental states". Consciousness and cognition 36:498-507.

Cassam, Quassim. 2009. The Possibility of Knowledge. Oxford University Press.

Cole, Kenneth L, et al. 2011. "Past and ongoing shifts in Joshua tree distribution support future modeled range contraction". Ecological Applications 21 (1): 137-149.

Connolly, Kevin. 2014. "Perceptual learning and the contents of perception". Erkenntnis 79 (6): 1407-1418.

De Vignemont, Frederique, and Tania Singer. 2006. "The empathic brain: how, when and why?" Trends in cognitive sciences 10 (10): 435-441.

Dretske, Fred. 1969. Seeing and knowing. Routledge.

Fodor, Jerry. 2004. "Having concepts: A brief refutation of the twentieth century". Mind $\mathcal{E}$ Language 19 (1): 29-47.

Gallagher, Shaun. 2007. "Simulation trouble". Social Neuroscience 2 (3-4): 353-365.

— . 2008. "Direct perception in the intersubjective context". Consciousness and cognition 17 (2): 535-543.

Gallagher, Shaun, and Daniel Hutto. 2008. "Understanding others through primary interaction and narrative practice". The shared mind: Perspectives on intersubjectivity 12:1738.

Glazer, Trip. 2018. "The part-whole perception of emotion". Consciousness and cognition 58:34-43.

Green, Mitchell. 2010. “Perceiving Emotions”. In Aristotelian Society Supplementary Volume, 84:45-61. 1. Oxford University Press Oxford, UK.

Hatfield, Elaine, John T Cacioppo, and Richard L Rapson. 1993. "Emotional contagion". Current directions in psychological science 2 (3): 96-100. 
Hatfield, Gary. 2002. "Perception as unconscious inference". In Perception and the physical world: Psychological and philosophical issues in perception. Citeseer.

Helmholtz, Hermann von. 1867/1924. Treatise on physiological optics. Trans. by James P.C. Southall. Translated from the 3d German Ed. Optical Society of America.

Hohwy, Jakob. 2013. The predictive mind. Oxford University Press.

Kleffner, Dorothy A, and Vilayanur S Ramachandran. 1992. “On the perception of shape from shading". Perception \& Psychophysics 52 (1): 18-36.

Loar, Brian. 1990. "Phenomenal states". Philosophical perspectives 4:81-108.

Macpherson, Fiona. 2012. “Cognitive penetration of colour experience: Rethinking the issue in light of an indirect mechanism". Philosophy and Phenomenological Research 84 (1): $24-62$.

Martin, MGF. 2010. “What's in a Look?" In Perceiving the World, ed. by Bence Nanay. Oxford University Press.

McDowell, John. 1982. "Criteria, defeasibility, and knowledge". Studies in the Philosophy of Logic and Knowledge 68:455-79.

McNeill, William. 2015. "Inferentialism and our knowledge of others' minds". Philosophical Studies 172 (6): 1435-1454.

— . 2019. "Expressions, Looks and, Others' Minds". In Knowing Other Minds, ed. by Anita Avramides and Matthew Parrott. Oxford University Press.

Neufeld, Eleonore. 2018. "Can we perceive mental states?" Synthese: 1-25.

Nida-Rümelin, Martine. 2004. "What Mary Couldn't Know: Belief About Phenomenal States". In There's Something about Mary: Essays on Phenomenal Consciousness and Frank Jackson's Knowledge Argument, ed. by Daniel Stoljar Peter Ludlow Yujin Nagasawa. MIT Press.

Noë, Alva. 2005. "Real presence”. Philosophical Topics 33 (1): 235-264.

Nozick, Robert. 1981. Philosophical explanations. Harvard University Press.

Parkinson, Brian. 2011. "Interpersonal emotion transfer: Contagion and social appraisal". Social and Personality Psychology Compass 5 (7): 428-439.

Parrott, Matthew. 2017. “The Look of Another Mind". Mind 126 (504): 1023-1061.

Peacocke, Christopher. 1992. A study of concepts. The MIT Press.

— . 2001. "Does perception have a nonconceptual content?" The journal of philosophy 98 (5): 239-264.

Price, Richard. 2009. "Aspect-switching and visual phenomenal character". The Philosophical Quarterly 59 (236): 508-518.

Prinz, Jesse. 2013. “Siegel's get rich quick scheme". Philosophical Studies 163 (3): 827-835. 
Prinz, Jesse J. 2007. “All consciousness is perceptual". In Contemporary Debates in Philosophy of Mind, ed. by Brian P. McLaughlin and Jonathan Cohen. John Wiley \& Sons.

Pryor, James. 2000. "The skeptic and the dogmatist". Nô̂s 34 (4): 517-549.

— . 2005. "There is immediate justification". In Contemporary Debates in Epistemology, ed. by John Turri Matthias Steup and Ernest Sosa. John Wiley \& Sons.

Quilty-Dunn, Jake, and Eric Mandelbaum. 2018. “Inferential transitions". Australasian Journal of Philosophy 96 (3): 532-547.

Ramachandran, Vilayanur S. 1988a. "Perceiving shape from shading". Scientific American 259 (2): 76-83.

— . 1988b. "Perception of shape from shading". Nature 331 (6152): 163.

Siegel, Susanna. 2006. "Which properties are represented in perception". In Perceptual Experience, ed. by Tamar S. Gendler and John Hawthorne. Routledge.

— . 2011. The contents of visual experience. Oxford University Press.

— . 2012. "Cognitive penetrability and perceptual justification". Noûs 46 (2): 201-222.

— . 2016. The rationality of perception. Oxford University Press.

Siegel, Susanna, and Nicholas Silins. 2015. "The epistemology of perception". In The Oxford Handbook of the Philosophy of Perception, ed. by Mohan Matthen. Oxford University Press.

Smith, Joel. 2015. "The phenomenology of face-to-face mindreading". Philosophy and Phenomenological Research 90 (2): 274-293.

Smithies, Declan. 2011. "What is the role of consciousness in demonstrative thought?" The Journal of Philosophy 108 (1): 5-34.

— . 2013. "The nature of cognitive phenomenology". Philosophy Compass 8 (8): 744-754.

— . 2016. "Perception and the external world". Philosophical Studies 173 (4): 1119-1145.

Spaulding, Shannon. 2015. “On direct social perception”. Consciousness and Cognition 36:472482.

— . 2017. "On whether we can see intentions". Pacific Philosophical Quarterly 98 (2): 150170.

Wisdom, John, et al. 1946. "Symposium: other minds". Proceedings of the Aristotelian Society, Supplementary Volumes: 122-197.

Wittgenstein, Ludwig. 1980. "Remarks on the Philosophy of Psychology". 